\title{
Genetic variability in the tolerance of natural populations of Simocephalus vetulus (Müller, 1776) to lethal levels of sodium chloride
}

\author{
Cláudia Loureiro ${ }^{1}$, Bruno B. Castro ${ }^{1 *}$, Maria Teresa Claro ${ }^{1}$, Artur Alves ${ }^{1}$, M. Arminda Pedrosa ${ }^{2}$ \\ and Fernando Gonçalves ${ }^{1}$ \\ ${ }^{1}$ Department of Biology and CESAM, University of Aveiro, Campus Universitário de Santiago, 3810-193 Aveiro, Portugal \\ ${ }^{2}$ Unidade de I\&D No. 70/94 - Química-Física Molecular/FCT, MCT, Departamento de Química, Faculdade de Ciências e Tecnologia, \\ Universidade de Coimbra, Portugal
}

Received 26 April 2011; Accepted 26 October 2011

\begin{abstract}
Using several clonal lineages of Simocephalus vetulus (Cladocera, Daphniidae) as a random sample, we investigated the genetic component of the halotolerance of one brackish and two freshwater populations of this littoral filter feeder. We hypothesized that genotypes from the brackish population were more tolerant than freshwater ones, via adaptation to local environmental conditions. Clonal identity was established by a cost-effective molecular fingerprinting technique (microsatellite-primed polymerase chain reaction (MSP-PCR)). Two distinct methodologies were used to assess cladoceran sensitivity to syntheticgrade sodium chloride $(\mathrm{NaCl}$ ): (i) standard 48-h acute assays and (ii) 12-h survival time (ST) trials. No correlation was found between acute $\mathrm{EC}_{50}$ and $\mathrm{ST}$ values. The sensitivity of brackish and freshwater clones was comparable in terms of acute $\mathrm{EC}_{50}$ (varied from 2.28 to $3.83 \mathrm{~g} . \mathrm{L}^{-1}$ ). On the contrary, genetically determined differential tolerance to $\mathrm{NaCl}$ among populations was found for ST: all brackish genotypes, except one, were more resilient (ST $>120 \mathrm{~min}$ ) than freshwater clones (ST $<120 \mathrm{~min}$ ). Bearing in mind that these results were obtained with isolates from the extant population, it is surprising that the range of acute sensitivity of the freshwater and brackish genotypes was similar, and that the only difference between them was the ability of brackish clones to survive longer under high salinity stress (6 g. $\mathrm{L}^{-1}$, in ST trials). We must conclude that the effect of salinity (original environment context) on the selection of genotypes was weaker than we had expected and than other authors have shown for other stressors.
\end{abstract}

Key words: Genetic variability / genotype-environment interaction / sodium chloride / halotolerance / Simocephalus vetulus

\section{Introduction}

Saline intrusion in freshwaters has received considerable attention (e.g., Schallenberg et al., 2003; Sarma et al., 2006; Gonçalves et al., 2007; Nielsen et al., 2008), justified by the predictions of sea level rise and observation of coastal erosion, which threaten coastal lakes (IPCC, 2008). In coastal lakes that face regular (e.g., tidal) or sporadic salinity increases, freshwater organisms must cope with potentially lethal levels of salinity for short-term periods (hours to days). Particularly for large cladocerans (such as Daphnia and Simocephalus), their ability to survive (or not) these salinity pulses may modulate zooplanktonic taxa succession (Jeppesen et al., 1994, 2007; Schallenberg

\footnotetext{
*Corresponding author: brunocastro@ua.pt
}

et al., 2003; Nielsen et al., 2008) and a lake regime shift (see Jeppesen et al., 2007).

Although sensitive to minor salinity increases (Schallenberg et al., 2003; Sarma et al., 2006; Gonçalves et al., 2007), freshwater cladoceran populations also occur in coastal systems with distinct degrees of connectedness to the sea (e.g., Jeppesen et al., 1994; Schallenberg et al., 2003; Marques et al., 2006; Santangelo et al., 2008). Such physiological plasticity is likely due to genetic factors associated with osmoregulation shifts (Arnér and Koivisto, 1993; Aladin and Potts, 1995; Martínez-Jerónimo and Martínez-Jerónimo, 2007). The degree of phenotypic plasticity to environmental fluctuations is naturally framed within the populations' genetic variability, which is greatly influenced by founder effects and locally acting selective forces (De Meester, 1996a, 1996b; Boersma et al., 1999; 
De Meester et al., 2002). Many studies have shown that locally acting selective forces (particularly predation) lead to the formation of local races or "ecotypes" (local adaptation, see Weider and Hebert, 1987; De Meester, 1996a, 1996b; Boersma et al., 1999; Cousyn et al., 2001; De Meester et al., 2002). This has also been reported in Daphnia populations from brackish vs. freshwater environments (Weider and Hebert, 1987; Teschner, 1995; Barry et al., 2005).

In this study, Simocephalus vetulus (Müller, 1776) (Cladocera, Daphniidae) populations inhabiting coastal lakes were used as an experimental model. Our interest was focused on a population inhabiting a brackish lagoon in the South of Portugal, which had to cope with salinities close to 2. Our main goal was to determine whether there is a genetic component of salinity resistance in this population. Since these populations are subjected to salinity pulses, due to the heterogeneous and challenging habitat they live in, they must be able to cope with short-term lethal levels of salinity. Therefore, our aim was to compare the acute halotolerance with salinity (using $\mathrm{NaCl}$ as a proxy) of this brackish population with that of freshwater populations of $S$. vetulus. To do so, two distinct methodologies were employed: (i) standard acute assays (OECD, 2004), complemented with (ii) survival time (ST) trials (adapted from Ribeiro et al., 2000; Lopes et al., 2005). We hypothesized that there should be a population differentiation pattern in terms of acute halotolerance, with brackish genotypes being more resilient to $\mathrm{NaCl}$ than freshwater ones.

Studies concerning genetic differentiation in quantitative traits of cladocerans have been conducted in daphniids (Cladocera, Daphniidae) living in contaminated vs. uncontaminated habitats (e.g., Lopes et al., 2005; Muyssen et al., 2005) and fish vs. fishless lakes (e.g., De Meester, 1996a; Boersma et al., 1999). Such studies rely on the parthenogenetic mode of reproduction, short life cycle and ease in laboratory culturing of cladocerans (Muyssen et al., 2005), which assure continuous rearing of progeny bearing the genetic information of the founding mothers (De Meester, 1996a; Pfrender and Lynch, 2000). By maintaining clonal lineages under similar laboratory conditions for several generations, environmental and maternal effects can thus be eliminated.

\section{Material and methods}

\section{Cultures and test organisms}

S. vetulus (Müller, 1776) occupies a different ecological niche from most daphniids, due to its habitat preferences and swimming behaviour (Alonso, 1996). It is a macrophyte-associated filter feeder and an important regulator of primary production and nutrient cycling in littoral habitats (Hann, 1995; Alonso, 1996). Clonal lineages of $S$. vetulus were established from three extant populations, which were sampled with oblique trawls of plankton net. Two of these populations came from coastal freshwater ecosystems in central Portugal, namely a small shallow lake (Lagoa de Mira - LM; lat. 40 $26^{\prime} 29^{\prime \prime} \mathrm{N}$, long. $\left.8^{\circ} 45^{\prime} 09^{\prime \prime} \mathrm{W}\right)$ and a nearby semi-artificial ditch or canal (Vala da Fervença - VF; lat. 40² $25^{\prime} 36^{\prime \prime} \mathrm{N}$, long. $8^{\circ} 45^{\prime} 19^{\prime \prime} \mathrm{W}$ ). Although there is hydrological connectivity between these systems and the Ria de Aveiro estuary (i.e., indirect connection with the marine environment via a semiartificial system of small ditches and channels), salinity does not reach upstream due to a system of small dams and dikes. Thus, there is low dissolved solids concentration and conductivity is typically $<500 \mu \mathrm{S} . \mathrm{cm}^{-1}$. The third population originated from inhabitants of a brackish lagoon (Lagoa de Melides - M; lat. 38 $08^{\prime} 01^{\prime \prime} \mathrm{N}$, long. $\left.8^{\circ} 46^{\prime} 52^{\prime \prime} \mathrm{W}\right)$. This coastal lake has an intermittent connection with the sea (usually once or twice a year, either by human or natural action). Samples were taken at the farthest point from the sea entrance, where salinity was 2.3 .

Field-collected samples were immediately brought to the laboratory, where a random subsample of ovigerous mothers was isolated from each lake and transferred to $50 \mathrm{~mL}$ glass beakers with lake water. As a starting point, we assumed each mother to represent a putatively distinct genotype, until genetic fingerprinting tools clarified clonal identity (see below). Asexually produced newborns ( $F_{0}$ generation) from these mothers were used as starting inocula of monoclonal cultures. The genotype collections of $S$. vetulus were reared in moderately hard reconstituted water ( $\mathrm{pH} 7.4-7.8$, hardness 80-100 mg.L ${ }^{-1} \mathrm{CaCO}_{3}$, alkalinity $57-64 \mathrm{mg} . \mathrm{L}^{-1} \mathrm{CaCO}_{3}$ ), comprised of: $123 \mathrm{mg} . \mathrm{L}^{-1}$ $\mathrm{MgSO}_{4} \cdot 7 \mathrm{H}_{2} \mathrm{O}, \quad 96 \mathrm{mg} . \mathrm{L}^{-1} \quad \mathrm{NaHCO}_{3}, \quad 60 \mathrm{mg} . \mathrm{L}^{-1}$ $\mathrm{CaSO}_{4} \cdot 2 \mathrm{H}_{2} \mathrm{O}$, and $4 \mathrm{mg} . \mathrm{L}^{-1} \mathrm{KCl}$, sensu ASTM (1980) and USEPA (2002). This synthetic medium was supplemented with $4 \mathrm{~mL} . \mathrm{L}^{-1}$ of a standard organic additive (algal extract as described by Baird et al., 1989) and vitamins (as described for M4 and M7 medium - Elendt and Bias, 1990). Cyclically, neonates from the third or fourth brood were isolated and their mothers discarded, thus providing continuous culture renewal $\left(F_{1}\right.$, $\left.F_{2}, F_{3}, \ldots\right)$ for at least 10 generations. This provided a required refractory period, ensuring normalization of environmental and maternal influences; both freshwater and brackish genotypes were cultured in the described freshwater reconstituted medium. Cultures were reared under a temperature of $20 \pm 2{ }^{\circ} \mathrm{C}$ and a $16 \mathrm{~h}^{\mathrm{L}}: 8 \mathrm{~h}^{\mathrm{D}}$ photoperiod, and organisms were fed three times a week (Monday, Wednesday and Friday) with a Pseudokirchneriella subcapitata ration of $1.5 \times 10^{5}$ cells. $\mathrm{mL}^{-1}$ (for more information on algal culture and ration, see Antunes et al., 2004). Vessels with acclimated animals were used as stock cultures for all subsequent experiments.

\section{Clonal identification}

Microsatellite-primed polymerase chain reaction (MSP-PCR) or inter-simple sequence repeats (ISSR) is a fast and simple genotyping technique that uses repetitive 
and highly variable regions of the genome (microsatellites) to design universal primers, which produce highly variable fingerprinting profiles (Zietkiewicz et al., 1994; Karp and Edwards, 1997; Abbot, 2001). This technique has shown to be useful in studies on systematics and in the differentiation of strains and breeds within the same species (e.g., Alves et al., 2007) and within cell lineages from the same individual (e.g., Grasela and McIntosh, 2003).

DNA was extracted individually from preserved specimens (in 70-80\% ethanol) of each population using a standard protocol (Schwenk et al., 1998), which has undergone minor adjustments over time (see Brede et al., 2006). To maximize extraction, only adult females were used and a preliminary step consisting of specimen maceration was included in the extraction procedure. All monoclonal cultures successfully established in the laboratory were analysed, in a total of 54 putative lineages (18 per population).

Each MSP-PCR reaction was performed in a total volume of $24 \mu \mathrm{L}$, containing $2.0 \mathrm{mM} \mathrm{MgCl}, 0.2 \mathrm{mM}$ dNTP, 1x PCR buffer, $0.3 \mu \mathrm{M}$ primer, and 1 unit of DNA polymerase (Go Taq Flexi DNA polymerase, Promega). Three primers $\left[(\mathrm{GTG})_{5},(\mathrm{CAG})_{6}\right.$ and $\left.(\mathrm{ACC})_{6}\right]$ were chosen to discriminate genotypes, after preliminary testing on PCR conditions and reproducibility of a wider battery of primers (see Abbot, 2001; Grasela and McIntosh, 2003; Dusinský et al., 2006; Alves et al., 2007). Cycling conditions were as follows: (i) a denaturation step consisting of one cycle of $120 \mathrm{~s}$ at $95^{\circ} \mathrm{C}$; (ii) 35 cycles of $45 \mathrm{~s}$ at $94^{\circ} \mathrm{C}, 45 \mathrm{~s}$ at $50^{\circ}$ or $57^{\circ} \mathrm{C}$ (depending on the primer used) and $90 \mathrm{~s}$ at $72^{\circ} \mathrm{C}$; (iii) a final elongation step of $10 \mathrm{~min}$ at $72{ }^{\circ} \mathrm{C}$. Primer (GTG) required an annealing temperature of $50^{\circ} \mathrm{C}$, while $(\mathrm{CAG})_{6}$ and (ACC) $)_{6}$ were amplified at $57^{\circ} \mathrm{C}$. PCR products were separated on $1.5 \%$ agarose gels (run at $90 \mathrm{~V}$ for $4 \mathrm{~h}$ ) and visualized under UV light, after immersion of gels in an ethidium bromide solution for $10 \mathrm{~min}$. A Promega loading buffer (Go Taq Flexi) was used and a $100 \mathrm{bp}$ molecular marker (100-1500 bp) was loaded in the gel as a reference.

The analysis of genetic variability among individuals was performed by comparison of the banding patterns obtained. The patterns were converted to a bidimensional binary matrix $(1=$ presence of band, $0=$ no band $)$. Samples were always run twice (amplification and fragment separation) and bands were only scored "1" if present in both amplifications. From this initial matrix, we derived similarity matrices using the Jaccard's coefficient (Culley, 2005), which allowed us to build dendrograms reflecting the genetic architecture of populations sampled. The dendrograms were constructed using unweighted pair group method with arithmetic mean (UPGMA). All analyses (gel and fingerprint data) were performed with GelCompar II (Applied Maths, USA), using its default optimization and tolerance levels. We used a conservative cut-off value ( $>30 \%$ dissimilarity) to differentiate clonal lineages, based on previous optimization of PCR consistency.
Table 1. Nominal concentrations $\left({ }^{\mathrm{a}}\right)$ of $\mathrm{NaCl}$ used in the halotolerance assays and respective salinity and electrical conductivity values in respective test media (mean of three measurements \pm standard deviation).

\begin{tabular}{lccc}
\hline Assays & $\begin{array}{c}{[\mathrm{NaCl}]^{\mathrm{a}}} \\
\left(\mathrm{g} . \mathrm{L}^{-1}\right)\end{array}$ & Salinity & $\begin{array}{c}\text { Conductivity } \\
\left(\mu \mathrm{S} . \mathrm{cm}^{-1}\right)\end{array}$ \\
\hline Acute assays & 0.0 & $0.0 \pm 0.00$ & $216.4 \pm 44.75$ \\
& 2.0 & $2.1 \pm 0.06$ & $3650 \pm 100.0$ \\
& 2.4 & $2.5 \pm 0.00$ & $4323 \pm 40.4$ \\
& 2.9 & $3.0 \pm 0.06$ & $5127 \pm 41.6$ \\
& 3.5 & $3.7 \pm 0.06$ & $6047 \pm 35.1$ \\
& 4.2 & $4.4 \pm 0.10$ & $7157 \pm 127.4$ \\
& 5.0 & $5.2 \pm 0.17$ & $8333 \pm 203.1$ \\
Survival-time & 6.0 & $6.3 \pm 0.06$ & $9977 \pm 98.2$ \\
trials & & & \\
\hline
\end{tabular}

aThe contribution of the test medium in terms of $\mathrm{Na}^{+}$and $\mathrm{Cl}^{-}$ was assumed to be unimportant, given the small amount of these ions in its composition (see text).

\section{Halotolerance assays}

Standard acute assays were conducted by exposing distinct $S$. vetulus clonal lineages (M63, M48, M66, M13, M7, M50, M20, M36, LM2, LM38, LM5, LM48, LM42, LM41, LM64, LM25, VF7, VF35, VF18, VF70, VF29, VF48 and VF69) to $\mathrm{NaCl}$ aqueous solutions, following standard protocols (ISO, 1996; USEPA, 2002; OECD, 2004). A stock solution $\left(50\right.$ g. $\left.\mathrm{L}^{-1}\right)$ was prepared by dissolving analytical grade $\mathrm{NaCl}$ in moderately hard reconstituted water. Test solutions (Tab. 1) were then obtained by diluting the appropriate volumes of stock solutions in the synthetic medium. Salinity and conductivity measurements were performed with a WTW conductivity meter. A fixed volume $(10 \mathrm{~mL}$ of test solution) was added to the corresponding test vessels. Neonates $(<24 \mathrm{~h}$ old and born between the 3rd and the 5th brood) were exposed to a geometric sequence of $\mathrm{NaCl}$ concentrations (2.0-5.0 g. $\mathrm{L}^{-1}$; Tab. 1), under the same conditions of rearing cultures. The range of concentrations used was selected based on preliminary tests and toxic levels reported in the literature (e.g., Gonçalves et al., 2007). Our goal was to find a range of concentrations which could be applied to all clones. Four replicates per treatment were used and five neonates were randomly assigned to each $10 \mathrm{~mL}$ replicate (i.e., a total of 20 organisms per test concentration were used). In all tests, a negative control was used, where no $\mathrm{NaCl}$ was added (nominal concentration 0.0 g. $\mathrm{L}^{-1}$; Tab. 1). Vessels were screened for immobilized daphniids after a $48 \mathrm{~h}$ exposure period. During these acute exposures, neither organic extract nor food was added.

ST trials were conducted with the same clonal lineages as the standard acute assays; experimental procedures were adapted from Ribeiro et al. (2000) and Lopes et al. (2005). Neonates (less than $24 \mathrm{~h}$ old and born between the third and the fifth brood) were exposed to a fixed concentration of $\mathrm{NaCl}\left(6.0\right.$ g. $\left.\mathrm{L}^{-1}\right)$, which is normally lethal within $12 \mathrm{~h}$. Salinity and conductivity measurements were also performed (Tab. 1). Assays were performed in 24-well 


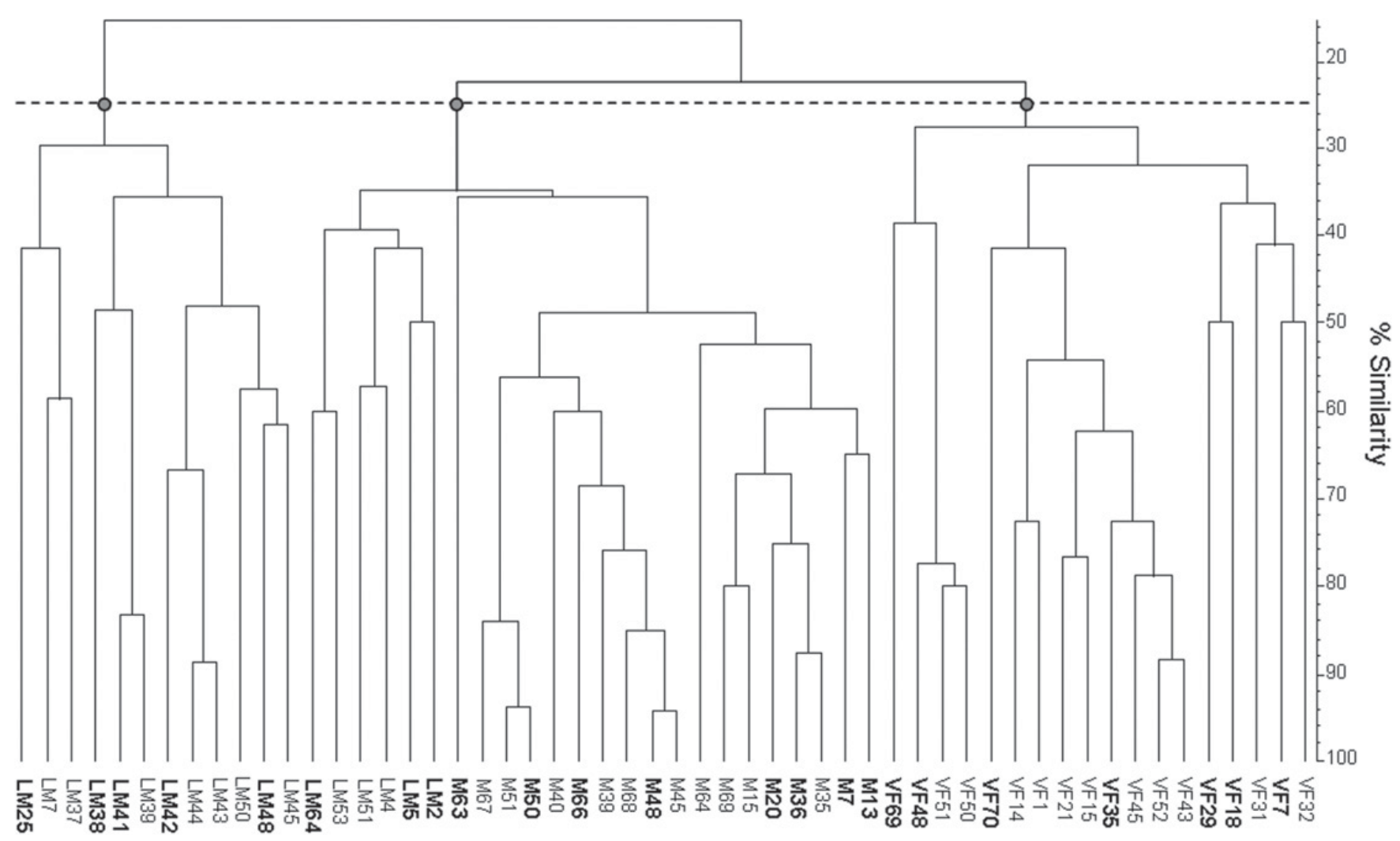

Fig. 1. Dendrogram of fingerprinting patterns of different individuals of $S$. vetulus from Melides lagoon (M), Mira lake (LM) and Fervença ditch (VF). Clones used in the experiments are shown in boldface.

cell culture plates, where six organisms of each clone were individually exposed to $2 \mathrm{~mL}$ of test medium (moderately hard reconstituted water spiked with $\mathrm{NaCl}$ ). Four genotypes could thus be tested in each plate. For each clone, trials were performed in triplicate, with each replicate consisting of neonates produced in different days or from different culture flasks of the same clone. Organisms were observed every $15 \mathrm{~min}$ from the beginning of the trial until $180 \mathrm{~min}$, every $30 \mathrm{~min}$ from 180 to $360 \mathrm{~min}$, every $1 \mathrm{~h}$ from 360 to $720 \mathrm{~min}$, and, if necessary, every $2 \mathrm{~h}$ after $720 \mathrm{~min}(12 \mathrm{~h})$. Similarly to the standard acute assays (see above), we used immobilization as the trial endpoint. Organisms were scored as immobile under the stereoscope $(8-10 \times$ magnification) if they were not able to swim after gentle and repeated prodding. Trials ended when all organisms were considered as immobilized in two consecutive observations. In parallel to all ST trials, controls (neonates exposed to unspiked culture medium) were performed, following the same experimental design; trials were valid only if no immobilized individuals were recorded in the control at the end of the test.

\section{Statistical analysis}

Acute toxicity was expressed as $48 \mathrm{~h}$ immobilization $\mathrm{EC}_{50}$ values (and respective $95 \%$ confidence intervals), as estimated with Probit analysis using Minitab ${ }^{\circledR}$ software. Average ST for each replicate and corresponding acute
$\mathrm{EC}_{50}$ values was integrated in the computation of a halotolerance index $(\mathrm{HI})$ :

$$
\mathrm{HI}=100 \times \operatorname{relST} \times \operatorname{relEC}_{50},
$$

where relST and relEC $\mathrm{E}_{50}$ represent the relative $\mathrm{ST}$ or $\mathrm{EC}_{50}$, i.e., the value of the clone under consideration divided by the maximum of all clones. This normalization step was introduced in the calculation to give similar weight to both variables, while allowing HI to vary between 100 (extreme tolerance) and close to 0 (extreme sensitivity). This weighed metric is thus a simple way to order genotypes in terms of their sensitivity.

ST was analysed for differences between populations, following a nested ANOVA design (mixed-effects model), with population as the fixed factor and clone (nested within population) and replicate trial (nested within clone) as the random factors. Individual ST measurements constituted the error term of the ANOVA. No replicates per clone were available for $\mathrm{EC}_{50}$ values, so a one-way ANOVA was used to assess differences among Simocephalus populations, using clone as the error term. All analyses were computed using Minitab ${ }^{\circledR}$ software, which also allowed extracting variance components for each source of variation.

\section{Results}

MSP-PCR band profiles allowed the differentiation of the three populations (Fig. 1). The only exception was a 
Table 2. Acute immobilization $\mathrm{EC}_{50}$ values (and respective $95 \%$ confidence intervals), $\mathrm{ST} \pm$ standard error, and $\mathrm{HI} \pm$ standard error for $S$. vetulus populations exposed to $\mathrm{NaCl}$. For each population, clones are sorted by descending $\mathrm{HI}$ (i.e., most tolerant clones on top).

\begin{tabular}{|c|c|c|c|c|}
\hline Population & Clone & Acute $\mathrm{EC}_{50}\left(\mathrm{~g} \cdot \mathrm{L}^{-1}\right)$ & ST (min) & HI \\
\hline \multirow[t]{8}{*}{ M (brackish) } & M63 & $2.90(2.61-3.17)$ & $241.0 \pm 41.77$ & $64.0 \pm 6.91$ \\
\hline & M48 & $3.52(3.31-3.77)$ & $163.3 \pm 18.70$ & $52.7 \pm 4.66$ \\
\hline & M66 & $3.07(2.76-3.38)$ & $165.0 \pm 17.45$ & $46.4 \pm 3.87$ \\
\hline & M13 & $3.83(3.63-4.05)$ & $124.2 \pm 19.13$ & $43.6 \pm 8.36$ \\
\hline & M7 & $3.65(3.43-3.90)$ & $112.5 \pm 8.68$ & $37.6 \pm 2.55$ \\
\hline & M50 & $2.76(2.55-2.96)$ & $145.8 \pm 13.33$ & $36.9 \pm 4.28$ \\
\hline & M20 & $2.77(2.59-2.95)$ & $129.2 \pm 4.40$ & $32.8 \pm 0.76$ \\
\hline & M36 & $2.48(2.22-2.70)$ & $131.7 \pm 10.88$ & $29.9 \pm 2.63$ \\
\hline \multirow[t]{8}{*}{ LM (freshwater) } & LM2 & $3.59(3.38-3.84)$ & $104.2 \pm 10.74$ & $34.3 \pm 6.01$ \\
\hline & LM38 & $3.51(3.31-3.75)$ & $105.0 \pm 7.70$ & $33.8 \pm 4.13$ \\
\hline & LM5 & $3.01(2.76-3.26)$ & $115.8 \pm 10.56$ & $31.9 \pm 5.34$ \\
\hline & LM48 & $3.45(3.20-3.73)$ & $91.7 \pm 7.85$ & $29.0 \pm 1.15$ \\
\hline & LM42 & $2.94(2.82-3.10)$ & $106.7 \pm 10.21$ & $28.7 \pm 3.02$ \\
\hline & LM41 & $2.82(2.52-3.04)$ & $103.3 \pm 8.12$ & $28.0 \pm 4.07$ \\
\hline & LM64 & $2.81(2.65-2.99)$ & $85.8 \pm 8.98$ & $22.1 \pm 3.51$ \\
\hline & LM25 & $3.04(2.83-3.28)$ & $76.7 \pm 5.93$ & $21.4 \pm 1.86$ \\
\hline \multirow[t]{7}{*}{ VF (freshwater) } & VF7 & $3.60(3.39-3.84)$ & $107.5 \pm 8.34$ & $35.5 \pm 5.30$ \\
\hline & VF35 & $2.74(2.09-2.81)$ & $114.2 \pm 12.49$ & $33.2 \pm 4.91$ \\
\hline & VF18 & $3.29(3.08-3.52)$ & $100.8 \pm 8.03$ & $30.4+4.23$ \\
\hline & VF70 & $2.63(2.35-2.87)$ & $116.7 \pm 12.22$ & $28.1 \pm 3.69$ \\
\hline & VF29 & $2.91(2.72-3.15)$ & $89.2 \pm 10.32$ & $23.8+1.56$ \\
\hline & VF48 & $2.28(1.50-2.55)$ & $101.7 \pm 18.53$ & $21.2+2.70$ \\
\hline & VF69 & $3.19(3.02-3.38)$ & $62.5 \pm 5.60$ & $18.3 \pm 2.77$ \\
\hline
\end{tabular}

subset of six LM genotypes, which was associated with the $\mathrm{M}$ population cluster. For this study, 23 clonal lineages (eight clones for $\mathrm{M}$, eight clones for LM and seven clones for VF) were used in the experiments (see list in Tab. 2), after being scored as genetically distinct genotypes (Fig. 1; the most similar genotypes used were M20 and M36). Genetic identity was confirmed by additional dendrograms for each population (data not shown), using a predetermined cutoff level of $70 \%$ similarity. This allowed a security margin in the discrimination of clones.

The acute immobilization $\mathrm{EC}_{50}$ values (Tab. 2 and Fig. 2) ranged from 2.28 to 3.83 g.. ${ }^{-1}$, thus demonstrating a large range of halotolerance in the tested genotypes. Comparing clone sensitivity within each population, the $\mathrm{EC}_{50}$ values obtained ranged from 2.48 to 3.83 g.L ${ }^{-1}$ in population $\mathrm{M}$ (brackish lagoon), 2.81 to $3.59 \mathrm{~g} . \mathrm{L}^{-1}$ for population LM (freshwater lake), and 2.28 to 3.60 g. $\mathrm{L}^{-1}$ in population VF (freshwater ditch). These ranges show an overlap of the values of halotolerance between populations (see distribution of clones in the x-axis of Fig. 2), confirming no differentiation between populations (oneway ANOVA: d.f. $=2,20 ; F=0.48 ; P=0.63$ ). Comparing all clones, the lowest $\left(2.28\right.$ g. $\left.\mathrm{L}^{-1}\right) \mathrm{EC}_{50}$ was observed in VF (a freshwater population), while the highest values (3.83 and 3.65 g. $\mathrm{L}^{-1}$ ) were recorded in clones from the brackish population (Tab. 2 and Fig. 2).

The $\mathrm{EC}_{50}$ values were not consistent with the halotolerance of clones in ST trials. In fact, the correlation between these variables (Fig. 2) was weak and not significant $(r=-0.083 ; P=0.71)$. A good example of this lack of correspondence is clone M63 (Fig. 2 and Tab. 2), which obtained an extreme ST value (241 min) but whose
$\mathrm{EC}_{50}$ was in the middle region of the plot $\left(2.9\right.$ g. $\left.\mathrm{L}^{-1}\right)$. Comparing clone sensitivity within each population, the ST values obtained ranged from 112.5 to $241 \mathrm{~min}$ in population M (brackish lagoon), 76.7 to $115.8 \mathrm{~min}$ for population LM (freshwater lake), and 62.5 to $116.7 \mathrm{~min}$ in population VF (freshwater ditch). These intervals showed that brackish clones were more halotolerant than the freshwater clones. The distribution of clones along the $\mathrm{y}$-axis of Figure 2 shows that ST of freshwater genotypes was always below $120 \mathrm{~min}$, while all brackish clones except M7 (ST=112.5 min) - displayed STs above this threshold. On average, clones from the brackish population $(\mathrm{M})$ resisted $1 \mathrm{~h}$ more than the two freshwater populations (Fig. 3). This produced statistically significant differences among populations (Tab. 3), despite intra-populational (clonal) variability. Indeed, interpopulational variability was higher than the within population variance component (17\% vs. $10 \%$; Tab. 3$)$.

HI values ranged from 29.9 to 64.0 for population $\mathrm{M}$ (brackish lagoon), 21.4 to 34.3 for population LM (freshwater lake), and 18.27 to 35.45 in population VF (freshwater ditch). Consistently with ST values, six out of eight genotypes from the brackish population scored the highest HI values (M20 and M36 were the exception) of all tested genotypes.

\section{Discussion}

Our study reports the differential tolerance to $\mathrm{NaCl}$ between one brackish and two freshwater populations of $S$. vetulus. All except one brackish genotype were able to 


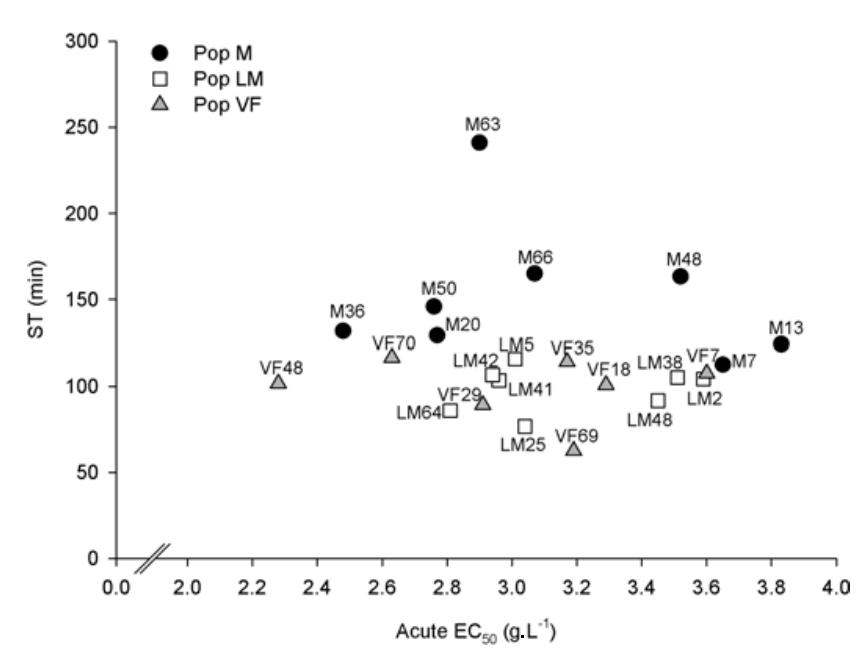

Fig. 2. Relative halotolerance of $S$. vetulus genotypes from three populations (M, LM, and VF): acute $\mathrm{EC}_{50}$ values vs. ST. Each circle, square, and triangle represents a genotype.

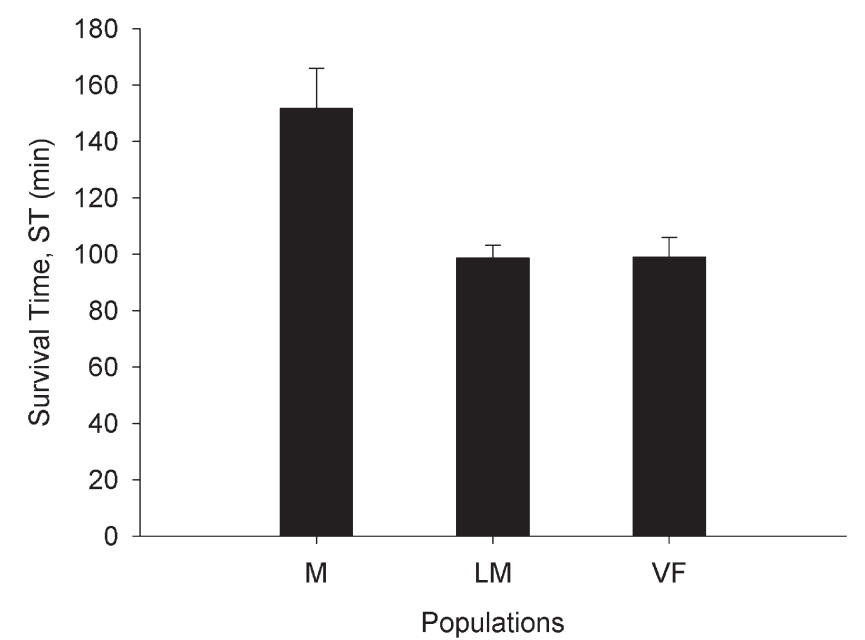

Fig. 3. Mean ST for each of the three populations studied (M, LM, and VF). Error bars represent standard error.

cope with high salinity stress $\left(6\right.$ g. $\left.\mathrm{L}^{-1}\right)$ for a longer period than freshwater genotypes, in ST trials. Since most maternal and environmental influences were previously discarded (by culturing clones for several generations under standardized conditions), these differences are assumed to be genetically determined. Therefore, this population differentiation pattern is shaped by locally-acting selective forces, in this case salinity. The increased resilience of brackish clones to high salinity levels, expressed as increased survivorship, is in agreement to what was found by Weider and Hebert (1987) and Teschner (1995) for Daphnia. Local selective forces play an important role in the genetic structure and diversity of invertebrate populations, especially those with reduced dispersal capabilities (De Meester, 1996b; De Meester et al., 2002, 2006). Thus, even minor salinity increments in freshwaters (of a progressive, long-term nature) may cause subtle impacts in animal populations, such as the appearance of
Table 3. Nested ANOVA summary tables for ST, including variance components (\%Var). ANOVA model includes a fixed factor (Pop - population) and two (Clone and Rep - replicate) nested random factors.

\begin{tabular}{llrrrrr}
\hline & Model & d.f. & Adj. MS & $F$ & $P$ & $\%$ Var \\
\hline ST & Pop & 2 & 130938 & 9.88 & 0.001 & 16.8 \\
& $\begin{array}{l}\text { Clone } \\
\text { (Pop) }\end{array}$ & 20 & 13254 & 3.48 & $<0.001$ & 10.4 \\
& & & & & \\
& Rep & 46 & 3807 & 1.04 & 0.412 & 0.45 \\
$\quad$ (Clone) & & & & & \\
Error & 345 & 3670 & & & \\
\hline
\end{tabular}

locally-selected races or "ecotypes" (sensu Weider and Hebert, 1987).

Unlike ST trials, no population differentiation pattern was found with standard acute assays. These contradictory results are portrayed by the lack of correspondence between acute $(48 \mathrm{~h}) \mathrm{EC}_{50}$ and $\mathrm{ST}$. In a work with D. longispina, Lopes et al. (2005) observed positive correlations between $\mathrm{LT}_{50}$ (lethal time) and $\mathrm{LC}_{50}$ (lethal concentration) only with copper, but not for zinc, cadmium, or hydrogen ions. Their original population was historically exposed to acid mine drainage contaminants, including copper and low $\mathrm{pH}$. The lack of association between moderately lethal and extremely lethal levels of stressors, such as metals or $\mathrm{pH}$ in the study by Lopes et al. (2005) and $\mathrm{NaCl}$ (in our study), has an unknown biological meaning. High stressor levels trigger fast-response genes, such as hormones or protective enzymes, which modulate behavioural and physiological responses to increase resistance to environmental stress (see Hoffmann and Parsons, 1993). In the case of metals and hydrogen ions - and probably $\mathrm{NaCl}$ - animals die out of a series of related complications besides ionoregulatory failure (Wilson and Taylor, 1993). Hence, the regulation mechanisms to moderately or extremely lethal levels of toxicants should be the same; thus, other explanations must be at the basis of the contradictory results observed for ST trials and standard acute assays. One hypothesis is that the lack of association between both endpoints is related to their temporal resolution (see below).

Differences in ST between freshwater and brackish populations were observed in a limited time scale, varying from minutes to a few hours (between 35 and $178 \mathrm{~min}$ ). Differences in sensitivity at such a time scale are not perceptible in standard acute exposures. In ST trials, a lethal concentration of $\mathrm{NaCl}$ is used and frequent measurements are taken, while in standard acute assays the organisms are checked at larger time intervals (24-48 h) after exposure to a range of increasing concentrations. There is considerable loss of information when daphniids are screened at such large time intervals ( $\geq 24 \mathrm{~h}$ ). Thus, the finer temporal resolution of ST trials seems theoretically more advantageous and sensitive than standard acute exposures for exploring differentiation in quantitative genetic traits. Also, ST allows one to analyse the data using an ANOVA approach to partition-associated 
sources of variation (as done here), which is powerful and useful.

In this study, field clones were isolated from extant populations. Alternatively, many authors (e.g., Teschner, 1995; De Meester, 1996a; Boersma et al., 1999; Barry et al., 2005) use resting eggs (which result from sexual reproduction) as source of isolates. Both the active and dormant population have been subjected to different selective forces in each habitat throughout generations (De Meester, 1996b; De Meester et al., 2002), with emphasis on salinity in this case. The active population is less diverse, as it is constituted by individuals that have been subjected to local forces also during their ontogeny (De Meester et al., 2006), passing through various bottlenecks (hatching success, ability to feed and grow, asexual reproductive success). Therefore, the genotypes used in this study are the most adapted to the specific habitat of origin (freshwater or brackish). Thus, it is surprising that the range of acute sensitivity of the isolated freshwater and brackish genotypes is similar, with the only difference between them being the ability of brackish clones to survive longer under high salinity stress $\left(6 \mathrm{~g} . \mathrm{L}^{-1}\right)$. This is contrary to the findings of Lopes et al. (2004, 2005), who found remarkable differences between the acute sensitivities to copper (using standard acute assays) of historically-stressed and reference populations. We must conclude that the effect of salinity (original environment context) on the selection of genotypes was weaker than we had expected and than other authors have shown for other stressors.

When genotypes are isolated from the extant population, such as the case, the use of molecular fingerprinting is essential to assure clonal identity, since active populations are a mix of parthenogenetic and sexual clones (De Meester et al., 2006). In this study, we used a simple and cost-effective technique (MSP-PCR), which allowed satisfactory discrimination of genotypes (clones), analogously to RAPD (e.g., Weber and Declerck, 1997), microsatellite (e.g., Chopelet et al., 2008), or allozyme (e.g., Weider and Hebert, 1987) analyses. However, a conservative approach was needed, both in terms of band profile analysis and dissimilarity cut-off level, in order to avoid false positives (i.e., scoring identical genotypes as distinct). A reproducibility analysis of the technique showed that caution is needed because of variability among amplifications (probably due to misprints during PCR). Nonetheless, a few markers allowed the successful differentiation of the three studied populations (except for a small group of LM genotypes), even among populations with some connectivity degree (LM and VF). Although this was not the purpose of the study, we foresee a potential application of this technique in the decomposition of the genetic architecture of daphniid natural populations, provided a more comprehensive set of markers is used and that the technique's reproducibility and amplification specificity are improved.

Acute $\mathrm{EC}_{50}$ for $S$. vetulus genotypes ranged between 2.3 and $3.8 \mathrm{~g} . \mathrm{L}^{-1}$ of $\mathrm{NaCl}$ in this study. This is in agreement with the microcosm experiments of Sarma et al. (2006), whose $S$. vetulus experimental populations barely survived at 4 g. $\mathrm{L}^{-1}$, but were able to reproduce up to a concentration of 2 g. $\mathrm{L}^{-1}$. Halotolerance values for other cladocerans have also been reported using laboratory assays. Martínez-Jerónimo and Martínez-Jerónimo (2007) reported a $48 \mathrm{~h} \mathrm{LC}_{50}$ of $5.48 \mathrm{~g} \mathrm{~L}^{-1}$ for D. magna, while demonstrating that acclimated organisms could survive and reproduce in $\mathrm{NaCl}$ concentrations up to 6 g. $\mathrm{L}^{-1}$. Gonçalves et al. (2007) reported an acute $48 \mathrm{~h} \mathrm{EC}_{50}$ of 2.9 and 5.9 g. $\mathrm{L}^{-1}$ for $D$. longispina and D. magna, respectively. These data suggest that $S$. vetulus halotolerance, regardless of their habitat of origin (brackish vs. freshwater), is comparable with that of $D$. longispina, and both are more sensitive than D. magna. Indeed, the latter species is documented to be halotolerant and is a common inhabitant of brackish lakes and rock pools (Arnér and Koivisto, 1993; Teschner, 1995; Alonso, 1996). Ceriodaphnia lacustris, D. thomsoni, D. pulex and D. pulicaria have also been found in habitats with moderate (5-13) salinities (Weider and Hebert, 1987; Barry et al., 2005; Northcote and Hall, 2010). However, most cladocerans are restricted to freshwater (Alonso, 1996) and are only able to cope with low salinities (usually $<2$; see Sarma et al., 2006) (for field data, see Jeppesen et al., 1994; Schallenberg et al., 2003; Marques et al., 2006; Santangelo et al., 2008). In fact, Schallenberg et al. (2003) predicts that severe alterations of zooplankton community structure and abundance may occur at salinities $>1.2$. These authors found Simocephalus sp. to tolerate salinities up to 1.2, while in our study $S$. vetulus occurred in Melides (population M) at a salinity of 2.3. However, we only found partial evidence that this population possesses genetically-determined tolerance mechanisms to endure saline stress, as portrayed by the lack of correspondence between standard acute assays (tolerance overlap) and ST (population differentiation).

Acknowledgements. Authors wish to thank the comments and suggestions from three anonymous reviewers, which produced considerable improvements to a previous version of the manuscript. This work was supported by Fundação para a Ciência e a Tecnologia in the form of a PhD grant to Cláudia Loureiro (SFRH/BD/36333/2007). Bruno B. Castro and Artur Alves are hired under the programme Ciência2008, co-funded by the Human Potential Operational Programme (National Strategic Reference Framework 2007-2013) and European Social Fund (EU). This work is part of the project Saltfree (PTDC/AAC-AMB/104532/2008), which is funded by FEDER through COMPETE-Programa Operacional Factores de Competitividade, by national funding from Fundação para a Ciência e a Tecnologia.

\section{References}

Abbot P., 2001. Individual and population variation in invertebrates revealed by inter-simple sequence repeats (ISSRs). J. Insect Sci., 1.8, 3.

Aladin N.V. and Potts W.T.W., 1995. Osmoregulatory capacity of the Cladocera. J. Comp. Physiol. B., 164, 671-683. 
Alonso M., 1996. Fauna Ibérica. Crustacea, Branquiopoda, vol 7. Museo Nacional de Ciencias Naturales. Consejo Superior de Investigaciones Científicas, Madrid, 486 p.

Alves A., Phillips A., Henriques I. and Correia A., 2007. Rapid differentiation of species of Botryosphaeriaceae by PCR fingerprinting. Res. Microbiol., 158, 112-121.

Antunes S.C., Castro B.B. and Goncalves F., 2004. Effect of food level on the acute and chronic responses of daphnids to lindane. Environ. Pollut., 127, 367-375.

Arnér M. and Koivisto S., 1993. Effects of salinity on metabolism and life history characteristics of Daphnia magna. Hydrobiologia, 259, 69-77.

ASTM, 1980. Standard Practice for Conducting Acute Toxicity Tests with Fishes, Macroinvertebrates and Amphibians. American Society for Testing and Materials, Philadelphia.

Baird D.J., Soares A.M.V.M., Girling A., Barber I., Bradley M.C. and Calow P., 1989. The long-term maintenance of Daphnia magna Straus for use in ecotoxicity tests: problems and prospects. In: Lokke H., Tyle H. and Bro-Rasmussen F. (eds.), Proceedings of the First European Conference on Ecotoxicology, Lyngby, 144-148.

Barry M.J., Tibby J., Tsitsilas A., Mason B., Kershaw P. and Heijnis H., 2005. A long term lake-salinity record and its relationships to Daphnia populations. Arch. Hydrobiol., 163, $1-23$.

Boersma M., De Meester L. and Spaak P., 1999. Environmental stress and local adaptation in Daphnia magna. Limnol. Oceanogr., 44, 393-402.

Brede N., Thielsch A., Sandrock C., Spaak P., Keller B., Streit B. and Schwenk K., 2006. Microsatellite markers for European Daphnia. Mol. Ecol. Notes, 6, 536-539.

Chopelet J., Blier P.U. and Dufresne F., 2008. Plasticity of growth rate and metabolism in Daphnia magna populations from different thermal habitats. J. Exp. Zool. A: Ecol. Genet. Physiol., 309A, 553-562.

Cousyn C., De Meester L., Colbourne J.K., Brendonck L., Verschuren D. and Volckaert F., 2001. Rapid, local adaptation of zooplankton behavior to changes in predation pressure in the absence of neutral genetic changes. Proc. Natl. Acad. Sci. USA, 98, 6256-6260.

Culley T.M. (2005) Population Genetic Analysis of ISSR Data. Available online http://www.artsci.uc.edu/collegedepts/ biology/fac_staff/culley/docs/Population $\% 20$ Genetic $\% 20$ Analysis \% 200f\%20ISSR \%20Data.pdf (accessed September 2011).

De Meester L., 1996a. Evolutionary potential and local genetic differentiation in a phenotypically plastic trait of a cyclical parthenogen, Daphnia magna. Evolution, 50, 12931298.

De Meester L., 1996b. Local genetic differentiation and adaptation in freshwater zooplankton populations: patterns and processes. Ecoscience, 3, 385-399.

De Meester L., Gómez A., Okamura B. and Schwenk K., 2002. The monopolization hypothesis and the dispersal-gene flow paradox in aquatic organisms. Acta Oecol. - Int. J. Ecol., 23, 121-135.

De Meester L., Vanoverbeke J., De Gelas K., Ortells R. and Spaak P., 2006. Genetic structure of cyclic parthenogenetic zooplankton populations - a conceptual framework. Arch. Hydrobiol., 167, 217-244.

Dusinský R., Kúdela M., Stloukalová V. and Jedlicka L., 2006. Use of inter-simple sequence repeat (ISSR) markers for discrimination between and within species of blackflies (Diptera: Simuliidae). Biologia, Bratislava, 61, 299-304.

Elendt B.P. and Bias W.R., 1990. Trace nutrient deficiency in Daphnia magna cultured in standard medium for toxicity testing. Effects of the optimization of culture conditions on life history parameters of D. magna. Water Res., 24, 1157-1167.

Gonçalves A.M.M., Castro B.B., Pardal M.A. and Gonçalves F., 2007. Salinity effects on survival and life history of two freshwater cladocerans (Daphnia magna and Daphnia longispina). Ann. Limnol. - Int. J. Limnol., 43, 13-20.

Grasela J.J. and McIntosh A.H., 2003. Application of intersimple sequence repeats to insect cell lines: identification at the clonal and tissue-specific level. Vitro Cell. Dev. Biol. Animal, 39, 356-363.

Hann B.J., 1995. Genetic-variation in Simocephalus (Anomopoda, Daphniidae) in North-America - patterns and consequences. Hydrobiologia, 307, 9-14.

Hoffmann A.A. and Parsons P.A., 1993. Evolutionary Genetics and Environmental Stress. Oxford University Press, New York, 296 p.

IPCC, 2008. Climate Change and Water - Technical Paper of the Intergovernmental Panel on Climate Change. IPCC Secretariat, Geneva.

ISO, 1996. Water Quality: Determination of the Inhibition of the Mobility of Daphnia Magna Straus (Cladocera, Crustacea) Acute Toxicity Test. Internacional Organization for Standardization, Geneva.

Jeppesen E., Sondergaard M., Kanstrup E., Petersen B., Eriksen R.B., Hammershoj M., Mortensen E., Jensen J.P. and Have A., 1994. Does the impact of nutrients on the biological structure and function of brackish and freshwater lakes differ?Hydrobiologia, 276, 15-30.

Jeppesen E., Sondergaard M., Pedersen A.R., Jurgens K., Strzelczak A., Lauridsen T.L. and Johansson L.S., 2007. Salinity induced regime shift in shallow brackish lagoons. Ecosystems, 10, 47-57.

Karp A. and Edwards K.J., 1997. DNA markers: a global overview. In: Caetano-Anollés G. and Gresshoff P.M. (eds.), DNA Markers: Protocols, Applications, and Overviews. Wiley-Liss, New York, 1-13.

Lopes I., Baird D.J. and Ribeiro R., 2004. Genetic determination of tolerance to lethal and sublethal copper concentrations in field populations of Daphnia longispina. Arch. Environ. Contam. Toxicol., 46, 43-51.

Lopes I., Baird D.J. and Ribeiro R., 2005. Genetically determined resistance to lethal levels of copper by Daphnia longispina: association with sublethal response and multiple/coresistance. Environ. Toxicol. Chem., 24, 1414-1419.

Marques S.C., Azeiteiro U.M., Marques J.C., Neto J.M. and Pardal M.A., 2006. Zooplankton and ichthyoplankton communities in a temperate estuary: spatial and temporal patterns. J. Plankton Res., 28, 297-312.

Martínez-Jerónimo F. and Martínez-Jerónimo L., 2007. Chronic effect of $\mathrm{NaCl}$ salinity on a freshwater strain of Daphnia magna Straus (Crustacea: Cladocera): a demographic study. Ecotoxicol. Environ. Saf., 67, 411-416.

Muyssen B.T.A., Bossuyt B.T.A. and Janssen C.R., 2005. Inter- and intra-species variation in acute zinc tolerance of field-collected cladoceran populations. Chemosphere, 61, $1159-1167$. 
Nielsen D.L., Brock M.A., Vogel M. and Petrie R., 2008. From fresh to saline: a comparison of zooplankton and plant communities developing under a gradient of salinity with communities developing under constant salinity levels. Mar. Freshw. Res., 59, 549-559.

Northcote T.G. and Hall K.J., 2010. Salinity regulation of zooplanktonic abundance and vertical distribution in two saline meromictic lakes in south central British Columbia. Hydrobiologia, 638, 121-136.

OECD, 2004. Daphnia sp., Acute Immobilization Test. Organization for the Economic Cooperation and Development, Paris.

Pfrender M.E. and Lynch M., 2000. Quantitative genetic variation in Daphnia: temporal changes in genetic architecture. Evolution, 54, 1502-1509.

Ribeiro R., Lopes I., Pereira A.M.M., Goncalves F. and Soares A.M.V.M., 2000. Survival time of Ceriodaphnia dubia in acid waters with metal contamination. Bull. Environ. Contam. Toxicol., 64, 130-136.

Santangelo J.M., Bozelli R.L., Rocha A.D. and Esteves F.D., 2008. Effects of slight salinity increases on Moina micrura (Cladocera) populations: field and laboratory observations. Mar. Freshw. Res., 59, 808-816.

Sarma S.S.S., Nandini S., Morales-Ventura J., Delgado-Martínez I. and González-Valverde L., 2006. Effects of $\mathrm{NaCl}$ salinity on the population dynamics of freshwater zooplankton (rotifers and cladocerans). Aquat. Ecol., 40, 349-360.

Schallenberg M., Hall C.J. and Burns C.W., 2003. Consequences of climate-induced salinity increases on zooplankton abundance and diversity in coastal lakes. Mar. Ecol. - Prog. Ser., 251, 181-189.

Schwenk K., Sand A., Boersma M., Brehm M., Mader E., Offerhaus D. and Spaak P., 1998. Genetic markers, genealogies and biogeographic patterns in the cladocera. Aquat. Ecol., 32, 37-51.

Teschner M., 1995. Effects of salinity on the life-history and fitness of Daphnia magna - variability within and between populations. Hydrobiologia, 307, 33-41.

USEPA, 2002. Methods for Measuring the Acute Toxicity of Effluents and Receiving Waters to Freshwater and Marine Organisms (5th edn), US Environmental Protection Agency, Washington.

Weber A. and Declerck S., 1997. Phenotypic plasticity of Daphnia life history traits in response to predator kairomones: genetic variability and evolutionary potential. Hydrobiologia, 360, 89-99.

Weider L.J. and Hebert P.D.N., 1987. Ecological and physiological differentiation among low-arctic clones of Daphnia pulex. Ecology, 68, 188-198.

Wilson R.W. and Taylor E.W., 1993. The physiological responses of freshwater rainbow trout, Oncorhynchus mykiss, during acutely lethal copper. J. Comp. Physiol. B., 163, 38-47.

Zietkiewicz E., Rafalski A. and Labuda D., 1994. Genome fingerprinting by simples sequence repeat (SSR)-anchored polymerase chain reaction amplification. Genomics, 20, 176-183. 